\title{
Impacts of Infectious Dose, Feeding Behavior, and Age of Culicoides sonorensis Biting Midges on Infection Dynamics of Vesicular Stomatitis Virus
}

\author{
Paula Rozo-Lopez ${ }^{1}$, Berlin Londono-Renteria ${ }^{1, *}$ id and Barbara S. Drolet ${ }^{2, * \mathbb{D}}$ \\ 1 Department of Entomology, Kansas State University, Vector Biology Laboratory, Manhattan, KS 66506, USA; \\ paularozo@ksu.edu \\ 2 Arthropod-Borne Animal Diseases Research Unit, Agricultural Research Service, United States Department of \\ Agriculture, Manhattan, KS 66502, USA \\ * Correspondence: blondono@ksu.edu (B.L.-R.); barbara.drolet@usda.gov (B.S.D.)
}

\section{check for}

updates

Citation: Rozo-Lopez, P.; Londono-Renteria, B.; Drolet, B.S. Impacts of Infectious Dose, Feeding Behavior, and Age of Culicoides sonorensis Biting Midges on Infection Dynamics of Vesicular Stomatitis Virus. Pathogens 2021, 10, 816 https://doi.org/10.3390/ pathogens 10070816

\section{Academic Editor:}

Andrew Taylor-Robinson

Received: 28 May 2021

Accepted: 27 June 2021

Published: 29 June 2021

Publisher's Note: MDPI stays neutral with regard to jurisdictional claims in published maps and institutional affiliations.

Copyright: (c) 2021 by the authors. Licensee MDPI, Basel, Switzerland. This article is an open access article distributed under the terms and conditions of the Creative Commons Attribution (CC BY) license (https:/ / creativecommons.org/licenses/by/ $4.0 /)$.

\begin{abstract}
Culicoides sonorensis biting midges are biological vectors of vesicular stomatitis virus (VSV) in the U.S. Yet, little is known regarding the amount of ingested virus required to infect midges, nor how their feeding behavior or age affects viral replication and vector competence. We determined the minimum infectious dose of VSV-New Jersey for C. sonorensis midges and examined the effects of multiple blood-feeding cycles and age at the time of virus acquisition on infection dynamics. A minimum dose of 3.2 logs of virus $/ \mathrm{mL}$ of blood resulted in midgut infections, and $5.2 \operatorname{logs} / \mathrm{mL}$ resulted in a disseminated infection to salivary glands. For blood-feeding behavior studies, ingestion of one or two non-infectious blood meals (BM) after a VSV infectious blood meal (VSV-BM) resulted in higher whole-body virus titers than midges receiving only the single infectious VSV-BM. Interestingly, this infection enhancement was not seen when a non-infectious BM preceded the infectious VSVBM. Lastly, increased midge age at the time of infection correlated to increased whole-body virus titers. This research highlights the epidemiological implications of infectious doses, vector feeding behaviors, and vector age on VSV infection dynamics to estimate the risk of transmission by Culicoides midges more precisely.
\end{abstract}

Keywords: vesicular stomatitis virus; Culicoides midges; infectious dose; blood-feeding behavior; vector age

\section{Introduction}

Culicoides biting midges (Diptera: Ceratopogonidae) are significant agricultural pests and biological vectors of orbiviruses, orthobunyaviruses, bunyaviruses, and rhabdoviruses [1,2]. Specifically, in the U.S., Culicoides sonorensis midges play a critical role in the epidemiology of the rhabdovirus, vesicular stomatitis virus (VSV) [3-10]. Vesicular stomatitis (VS) is a viral disease of cattle, horses, sheep, goats, llamas, alpacas, and domestic and feral swine. Clinical disease includes excessive salivation and vesicular lesions of the gums, tongue, naso-oral mucosa, teats, and coronary bands, and is indistinguishable from foot-and-mouth disease in cattle and swine [11]. Economic losses are due to animal health effects, but most significantly from animal movement restrictions and quarantine measures. The epidemiology of VS is complex, involving multiple animal species, insect vectors, and routes of infection, requiring significant resources to monitor and predict outbreaks. While endemic in tropical and subtropical regions of the Americas [12], outbreaks in the U.S. with two main serotypes, VSV-New Jersey (VSV-NJ) and VSV-Indiana (VSV-IN), are sporadic occurring every 5-10 years. Incursions result from the northward movement of specific viral lineages from endemic regions of Central and Northern Mexico when ideal ecological conditions exist $[5,11,13,14]$.

Vector-borne disease transmission dynamics depend on virus-vector interactions, namely the ability of the vector to replicate and transmit virus, and vector-host interactions, 
namely the frequency with which the vector encounters a susceptible animal for bloodfeeding. Although adult Culicoides females rely on the consumption of plant carbohydrates as an energy source, they ingest blood to obtain protein for egg-laying [15]. Female swarms opportunistically feed on a wide range of hosts every 3 to 5 days; however, most vector species preferentially feed on domestic and wild ruminants and on horses [16]. As is characteristic of pool-feeders, Culicoides midges use their mouthparts to cut the epidermis and ingest blood and potentially other skin surface contaminates that pool in the wound. This causes significant mechanical damage to the dermis and induces physiological and immunological responses favorable for rapid infection and systemic dissemination of arboviruses delivered during blood-feeding [17].

Infectious VSV particles have proven difficult to detect in the blood of infected animals with viral RNA readily detected in plasma or serum (RNAemia), possibly due to the action of the vertebrate complement system or other blood factors that interfere with laboratory virus isolation methods [18]. Vesicular lesions and saliva contain high, measurable virus titers, and contaminate skin surfaces where midges pool-feed [19]. For VSV acquisition, midges must feed on infected hosts that are shedding virus at titers high enough to be taken up in their 100-150 nL volume blood meal (BM) [20,21]. Ingested virus must survive the digestive environment of the midgut, infect the midgut epithelium, and result in progeny virus crossing the basal lamina layer to disseminate into the hemolymph and subsequently infect and replicate in surrounding tissues, including the salivary glands. The number of virions ingested during a BM likely determines the success of overcoming the vector's intrinsic immunological and physical barriers and influences the overall vector competence [22]. Thus, the number of infected midges resulting from a single swarmfeeding event depends on the viral load of the shedding animal, the efficiency of viral uptake, and intrinsic events within the vector.

The vector competence of $C$. sonorensis midges has been previously investigated in laboratory studies by providing a high titer single infectious BM to newly emerged females $[10,23]$. However, this reference scenario may underestimate the epidemiological importance of vector feeding behaviors, age, and blood meal infectious doses. The magnitude of ingested titers and the effects on viral replication rates and subsequent bite transmission are important parameters to determine vector competence and overall vector capacity [22,24]. Previous work in mosquitoes has shown a virus titer threshold requirement in the initial blood meal for successful viral replication in the midgut and further dissemination [22,25]. In most cases, the proportion of infected mosquitoes positively correlates with the virus dose ingested in artificial blood meals [26,27]. Although viremia titers and duration are unknown for clinically infected animals, vector species can become infected with low or undetectable viremias [28]. Therefore, it is necessary to explore the impact of VS viral doses on midge infection rates and transmission potential.

The gonotrophic cycle (GC) comprises the time from the ingestion of a BM to the egglaying event. Under natural conditions, Culicoides midges will feed multiple times during their three to six week lifespan sustaining multiple cycles [29]. The blood-feeding process itself influences pathogen amplification and dissemination in other vector species. In mosquitoes, every blood meal triggers physiological changes, such as mechanical distention of the midgut that induces apoptosis and regeneration of midgut epithelial cells [30-32] and may enhance the probability of viral infection. Thus, successive feeding cycles may alter the midgut permeability and enhance or accelerate virus dissemination [30-32]. Moreover, each blood meal also alters innate immune responses in mosquitoes, influencing the likelihood of pathogen replication [33-35]. Age-related decline in the immune responses, including levels of melanization [36,37], the number of circulating hemocytes [38], and the overall phagocytic capacity $[37,38]$, may contribute to increased mortality of older mosquitoes after a pathogenic challenge [37,38]. As Culicoides midges share many biological traits with mosquitoes, midges acquiring a VSV infection during their first blood meal may have increased potential for transmission through feeding-related and age-related mechanisms that favor virus amplification [39]. Therefore, investigating the impact of age and additional 
blood-feeding on midge infection are critical to estimating Culicoides-VSV transmission dynamics accurately.

\section{Results}

\subsection{Effect of Infectious Dose on C. sonorensis VSV Infection and Dissemination Rates}

Six serially diluted viremic blood meals ranging from 3.2 to $8.2 \log _{10}$ plaque-forming units (PFU) per $\mathrm{mL}$ were provided to $C$. sonorensis females. Immediately after feeding, the ingested virus titer was measured in individual fully engorged midges by plaque assay and cytopathic effect (CPE). All females fed to repletion on each of the six viral dilutions were positive for infectious virus as detected by CPE. However, quantitation of virus titers by plaque assay was only achieved for the higher infectious dose groups (Table 1). As expected, the mean titer of ingested VSV was highly correlated to infectious dose with the lowest detectable ingested mean titer of $1.7 \operatorname{logs} \mathrm{PFU} / \mathrm{mL}$ in whole-body homogenates (Table 1; Figure S1).

Ten days after feeding on an infectious meal, bodies and heads with salivary glands of individuals were assayed separately by RT-qPCR to determine midgut infection and dissemination for each infectious dose, respectively. Decreased rates of midgut and disseminated infections were detected with decreasing titers of the infectious VSV blood meal (VSV-BM). The minimum VSV-BM infectious dose to infect midge midguts $(30.8 \%)$ was $3.2 \log _{10} \mathrm{PFU} / \mathrm{mL}$ (Figure 1a). The minimum infectious dose to result in a disseminated infection to heads and salivary glands $(25 \%)$ was $5.2 \log _{10} \mathrm{PFU} / \mathrm{mL}$ (Figure $1 \mathrm{~b}$ ).

To further analyze the minimum infectious dose-response, a non-linear logistic regression model, using cycle threshold $(\mathrm{Ct})$ values, was used to estimate VSV dose-response for midgut infection (bodies) and dissemination (heads with salivary glands) 10 days after ingesting a VSV-BM (Figure 2a). Virus titers of bodies showed an exponential increase in infection with increasing oral infectious doses with the highest titers observed among the highest oral dose provided. The non-linear $\mathrm{Ct}$ curve for individual heads was used to estimate a VSV disseminated infection (i.e., potential transmission) dose-response. Virus titers of heads showed a logistic growth as a response to the oral infectious doses. Head titers reached a threshold (i.e., increased potential transmission) with oral doses above $7.2 \log _{10} \mathrm{PFU} / \mathrm{mL}$. Additionally, whole-body Ct values were analyzed to determine their best fit to the exponential curve of the bodies to estimate infection or of the heads to estimate dissemination. Regression analysis indicated that the best-fit model for whole-body $\mathrm{Ct}$ followed the logistic curve of heads with a steeper slope from growth to plateau phase after ingesting BM titers above $7.2 \log _{10} \mathrm{PFU} / \mathrm{mL}$ (Figure 2a). The steeper growth for the whole-body logistic curves is most likely due to the abrupt increase in virus quantities seen in individual bodies of midges fed with $8.2 \log _{10} \mathrm{PFU} / \mathrm{mL}$ of VSV (Figure 2a). A non-linear regression model analysis was also used to calculate the oral infectious dose required for VSV to infect $50 \%$ of the bodies (OID50) and the oral infection dose required for VSV to disseminate in $50 \%$ of heads (ODD50) [40]. The detected OID50 was $5.8 \log _{10} \mathrm{PFU} / \mathrm{mL}$ and ODD50 was $6.3 \log _{10} \mathrm{PFU} / \mathrm{mL}$ (Figure $2 \mathrm{~b}$ ).

Table 1. Mean VSV titers of infectious blood meals and mean titers ingested by individual midges $(n=8)$ immediately after feeding as detected by plaque assay.

\begin{tabular}{ccc}
\hline $\begin{array}{c}\text { VSV-Blood Meal Titer } \\
\left(\log _{\mathbf{1 0}} \text { PFU/mL) }\right.\end{array}$ & $\begin{array}{c}\text { Mean VSV Ingested } \\
\left(\log _{\mathbf{1 0}} \text { PFU/mL) }\right)^{1}\end{array}$ & $\begin{array}{c}\text { Detected by } \\
\text { Plaque Assay+ } \mathbf{( \% )})\end{array}$ \\
\hline 8.2 & 5.5 & $8 / 8(100 \%)$ \\
7.2 & 4.1 & $8 / 8(100 \%)$ \\
6.2 & 3.3 & $8 / 8(100 \%)$ \\
5.2 & 2.5 & $5 / 8(62.5 \%)$ \\
4.2 & 1.9 & $3 / 8(37.5 \%)$ \\
3.2 & 1.7 & $1 / 8(12.5 \%)$ \\
\hline
\end{tabular}

${ }^{1}$ Mean ingested titer reported as PFU $/ \mathrm{mL}$ from the $500 \mu \mathrm{L}$ whole body midge homogenate. 
(a)

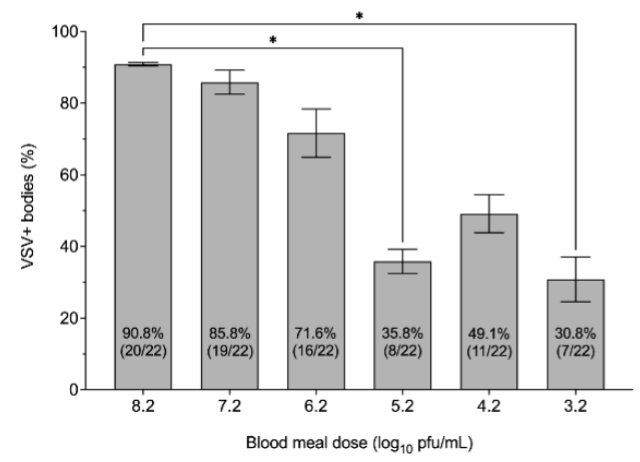

(b)

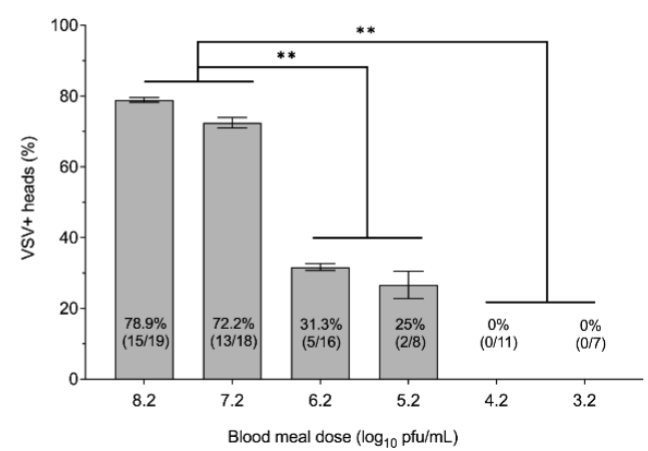

Figure 1. Effect of VSV blood meal infectious dose on midge midgut infection and dissemination rates at 10 days post-feeding as detected by RT-qPCR. (a) Proportional infection rates based on RNA detection in individual bodies. (b) Proportional dissemination rates based on RNA detection in individual heads with salivary glands. Statistical significance was determined by Kruskal-Wallis for multiple comparisons $\left({ }^{*} p \leq 0.05 ;{ }^{* *} p<0.01\right)$. Error bars represent the standard error of the mean (SEM).

(a)

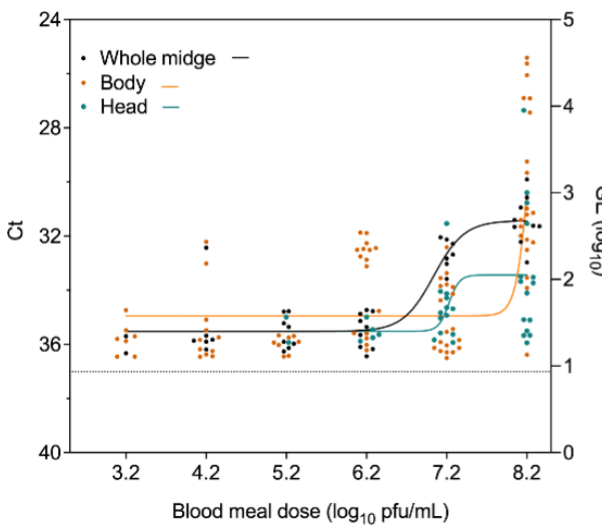

(b)

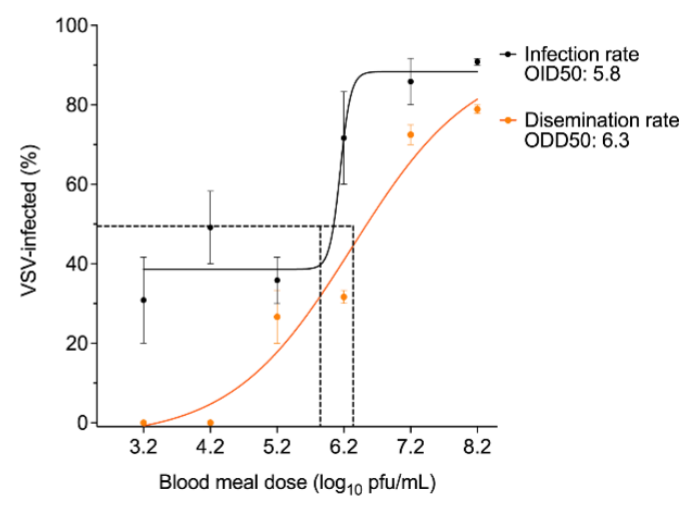

Figure 2. Logistic models for VSV infection and dissemination in midges at 10 days post-feeding. (a) RT-qPCR cycle threshold values (left Y-axis) and calculated $\log _{10}$ viral genome equivalents (right $\mathrm{Y}$ axis). Sigmoidal 4PL model (GraphPad) was used to perform the dose-Ct curve analysis ( $\mathrm{R}^{2}$ of whole midge $=0.83$, body $=0.50$, head $=0.31)$. $(\mathbf{b})$ Non-linear regression model of the oral dose vs. the mean percentage of infection indicating the oral infectious dose (OID50, $\mathrm{R}^{2}=0.84$ ) and oral dissemination dose (ODD50, $\left.\mathrm{R}^{2}=0.95\right)$.

\subsection{Effect of Subsequent or Prior Non-Infectious Blood Meals on C. sonorensis VSV Infection} Rates and Titers

Virus titers and infection rates of midges that fed on a single infectious blood meal (VSV-BM) were compared with age-matched midges that received one (VSV-BM + 1BM) or two (VSV-BM + 2BM) subsequent non-infectious blood meals (Figure 3a). Virus titers were significantly higher at $8 \mathrm{dpi}$ in the VSV-BM + 1BM group, and at $12 \mathrm{dpi}$ in the VSV-BM + 2BM group when compared to VSV-BM midges that received only the initial infectious meal (Kruskal-Wallis test; $p=0.028$ and 0.002, respectively) (Figure 4a). Higher overall infection rates were found in midges that received two additional non-infectious meals (Figure 4b) ( $p=0.007)$. Similarly, the VSV-BM + 1BM and VSV-BM + 2BM groups had a higher percentage of positive midges as detected by CPE in comparison to age-matched midges receiving only the initial infectious VSV-BM (Figure 5a); although not statistically significant $(p>0.05)$ due to high variability between individuals. Mean titers detected by plaque assay of original homogenates were 3.7 and $3.5 \log _{10}$ PFU/mL for $8 \mathrm{dpi}$ VSV-BM 
and VSV-BM + 1BM, respectively, and 4.6 and $4.2 \log _{10} \mathrm{PFU} / \mathrm{mL}$ for $12 \mathrm{dpi}$ VSV-BM and VSV-BM + 2BM, respectively.

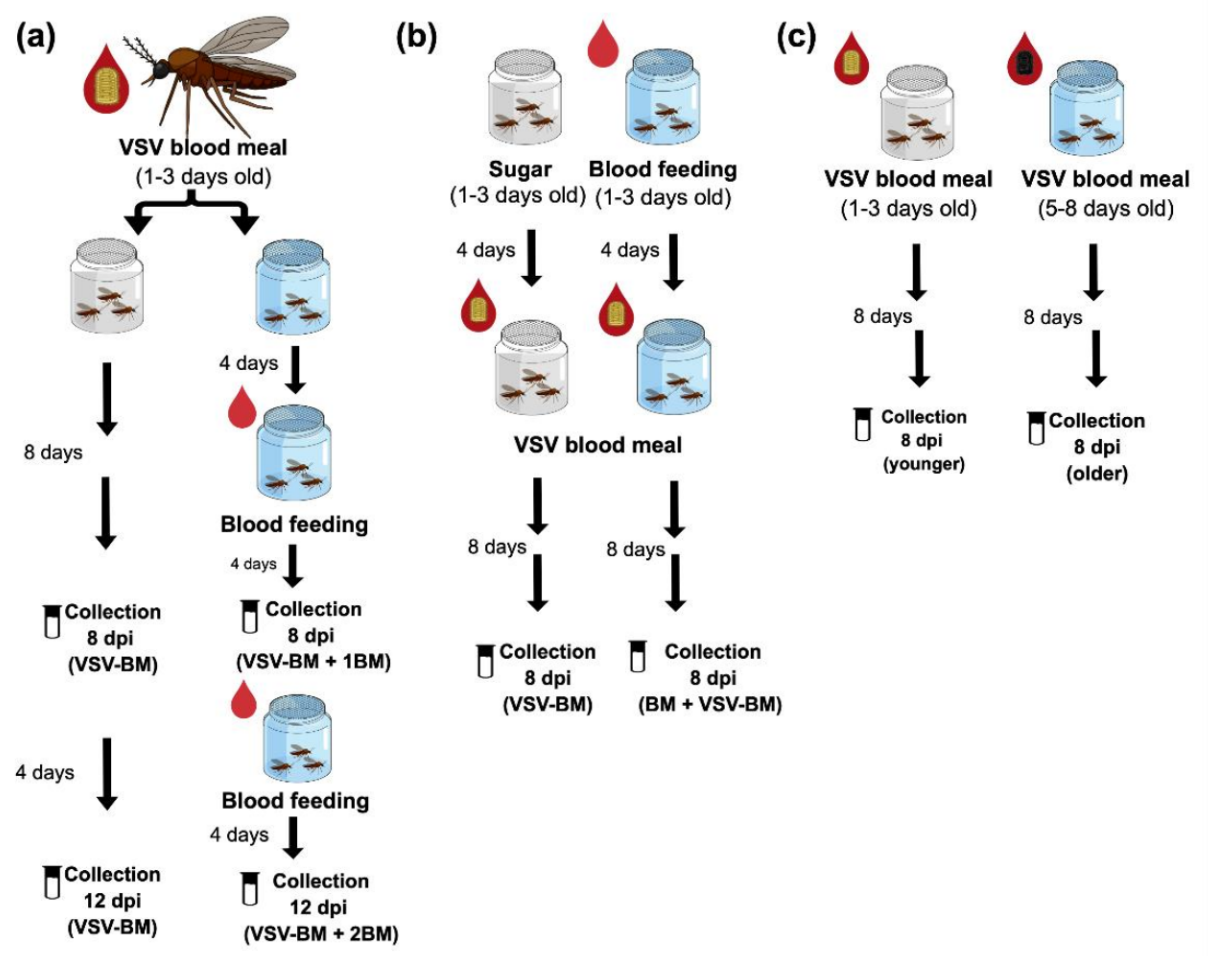

Figure 3. Experimental design to test the effect of (a) subsequent non-infectious feedings after oral infection, (b) VSV infection delivered as first or second blood meal, and (c) C. sonorensis age on VSV infection rates and viral titers.

(a)

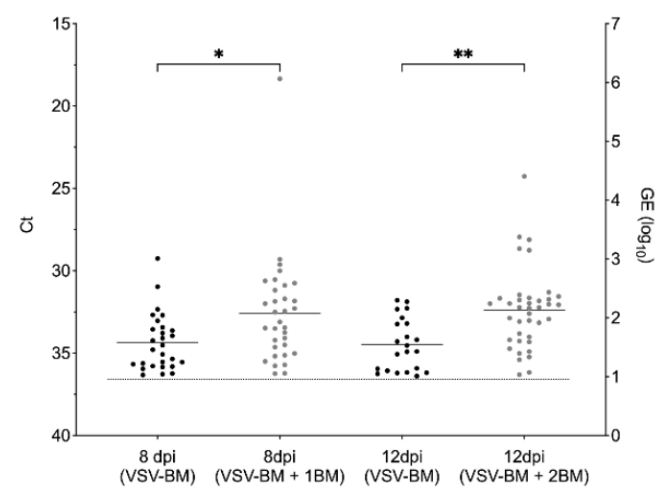

(b)

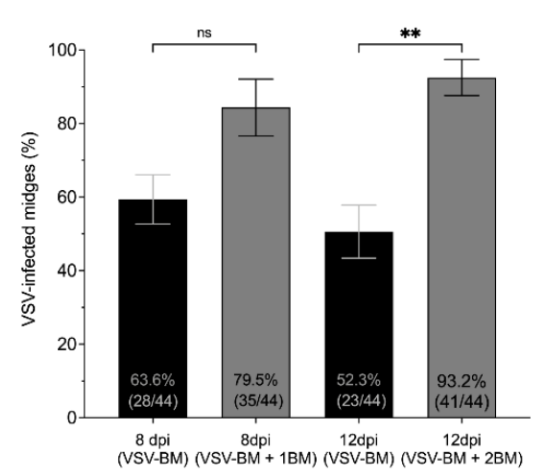

Figure 4. Effect of subsequent non-infectious blood meals (BM) on VSV titers and infection rates in midges as detected in whole bodies by RT-qPCR. (a) Detection of VSV RNA in whole midges at 8 and 12 days after having a single infectious blood meal (VSV-BM), one subsequent BM (VSV-BM + BM), or two subsequent BM (VSV-BM + 2BM). Cycle threshold values (left Y-axis) and calculated $\log _{10}$ viral genome equivalents (right Y-axis) as indicated. (b) Proportional infection rates for each treatment group at 8 and 12 days post-feeding. Kruskal-Wallis and multiple comparisons test used to determine statistical significance as indicated $\left(p>0.05\right.$, ns, not significant; $\left.{ }^{*} p \leq 0.05 ;{ }^{* *} p<0.01\right)$. Error bars represent the standard error of the mean (SEM). 
Virus titers and infection rates of midges provided one non-infectious BM prior to the infectious blood-meal (BM + VSV-BM) were compared with age-matched midges that received the infectious VSV-BM as their first meal (Figure 3b). At 8 dpi, no differences in virus titers or infection rates were observed between (VSV-BM) and (BM + VSV-BM) midges $(p>0.05)$ (Figure 6). Likewise, the proportion of VSV-positive midges as detected by CPE was similar in both groups $(p>0.05)$ (Figure $5 b$ ). Mean titers detected by plaque assay of original homogenates were $3.3 \log _{10} \mathrm{PFU} / \mathrm{mL}$ for both groups.

(a)

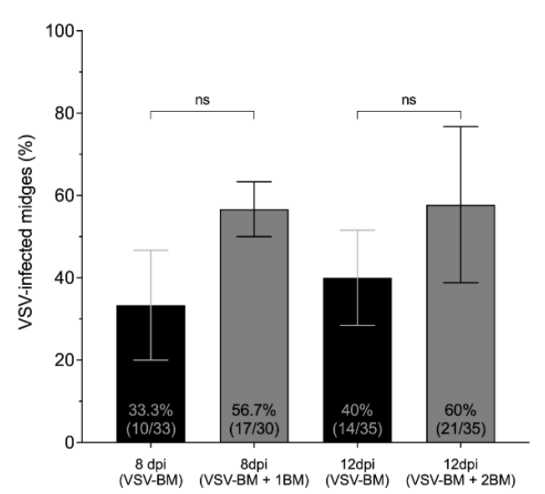

(b)

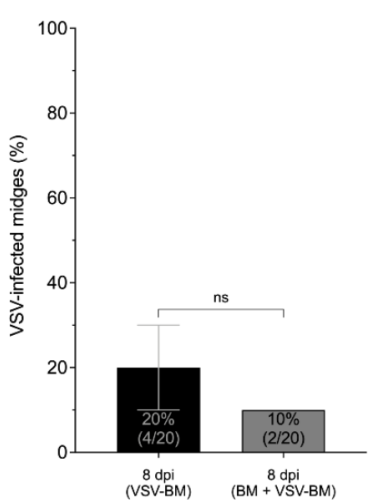

Figure 5. Infection rates of individual, orally infected midges as determined by cytopathic effect (CPE) screening of whole-body homogenates after two passages on Vero cells. (a) For subsequent meals, midges provided only a single infectious blood meal (VSV-BM) were compared to those receiving either one (VSV-BM + 1BM) or two (VSV-BM + 2BM) non-infectious blood meals at 8 and 12 days post-infection. (b) For prior blood meals, midges provided only a single infectious blood meal (VSV-BM) were compared to those receiving one prior non-infectious blood meal (BM + VSV-BM) at 8 days post-infection. Kruskal-Wallis and multiple comparisons test used to determine statistical significance as indicated ( $p>0.05, \mathrm{~ns}$, not significant). Error bars represent the standard error of the mean (SEM).

(a)

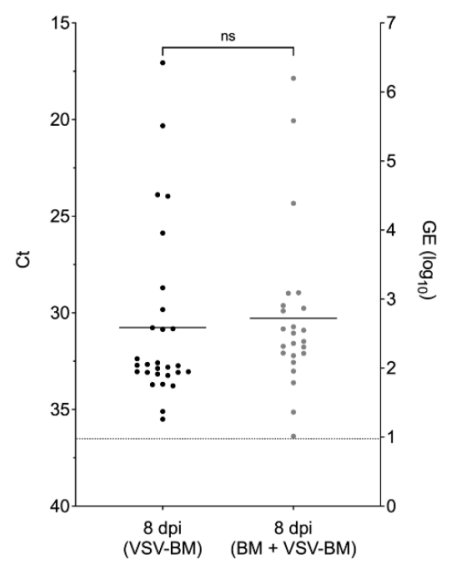

(b)

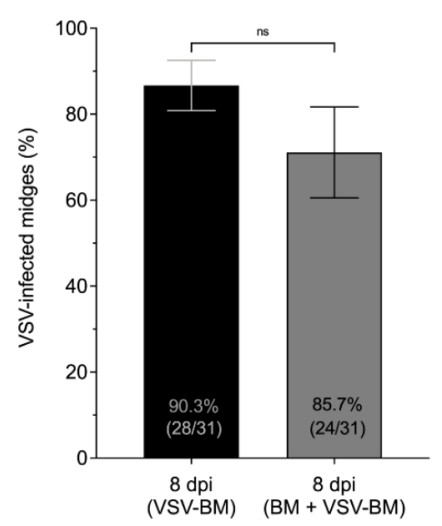

Figure 6. Effect of a prior non-infectious blood meal (BM) on VSV titers and infection rates of midges as detected in whole bodies by RT-qPCR. (a) Detection of VSV RNA in whole midges at 8 days after having a single infectious blood meal (VSV-BM) or having a non-infectious BM prior to the infectious meal (BM + VSV-BM). Cycle threshold values (left Y-axis) and calculated $\log _{10}$ viral genome equivalents (right Y-axis) as indicated. (b) Proportional infection rates for each treatment group at 8 days post-feeding. Mann-Whitney test was used for statistical significance as indicated ( $p>0.05$, ns, not significant). Error bars represent the standard error of the mean (SEM). 


\subsection{Effect of C. sonorensis Age on VSV Infection Rates and Titers}

Virus titers and infection rates of midges infected shortly after emergence (younger) and midges infected 5 to 8 days after emergence (older) were compared at 8 dpi (Figure 3c). Virus titers were significantly higher in older females in comparison to younger females $(p<0.0001)$ (Figure 7a). However, there was no significant difference in the proportional infection rates between age groups $(p>0.05)$ (Figure $7 \mathrm{~b})$.

(a)

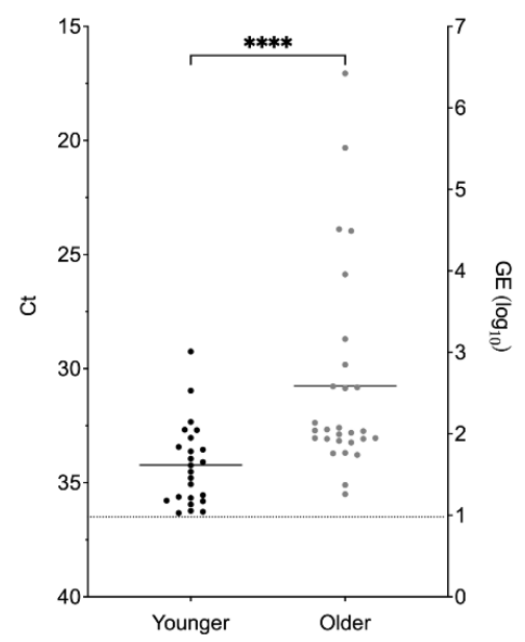

(b)

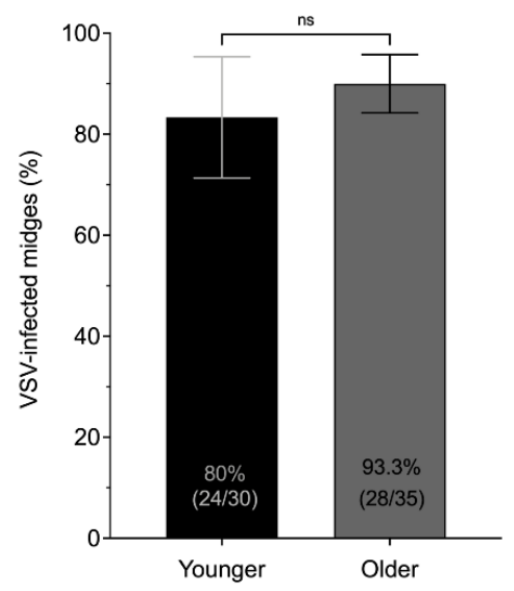

Figure 7. Effect of age on VSV titers and infection rates of midges as detected in whole bodies by RTqPCR. (a) Detection of VSV RNA in younger and older midges at $8 \mathrm{dpi}$. Cycle threshold values (left Y-axis) and calculated $\log _{10}$ viral genome equivalents (right Y-axis) as indicated. (b) Proportional infection rates for each age. Mann-Whitney test analysis for statistical significance as indicated $(p>0.05$, ns, not significant; $\left.{ }^{* * *} p \leq 0.0001\right)$. Error bars represent the standard error of the mean (SEM).

\section{Discussion}

Current understanding of the VSV infection dynamics within C. sonorensis is limited to studies on vector competence [10,23], bite transmission [9], and non-conventional routes of transmission [6]. The physiological consequences of viral dose, feeding behavior, and age on virus-vector interactions are lacking. We determined the minimum infectious dose for $C$. sonorensis midge infection and dissemination, examined the effects of prior and subsequent blood-feeding and the effects of age on VSV infection and dissemination. These results were compared to the traditional laboratory infection methods where newly emerged $C$. sonorensis females are fed with a single, high titer infectious blood-meal (VSV-BM).

The first determinant of vector competence evaluated in this study was the capacity of a newly emerged midge to become infected (VSV+ bodies) and have a disseminated infection (VSV+ heads) 10 days after feeding on 10-fold serially diluted infectious blood meals. Previous studies suggested that disseminated VSV infections correlate with salivary gland infection and transmission potential [10]; thus, we tested heads separate from the bodies to determine dissemination and transmission potential. We observed that higher virus titers enhance VSV infection and potential transmission while lower titers result in infections with limited dissemination, thus reducing the potential transmission. VSV+ midges were obtained for all infectious oral doses even as low as $3.2 \log _{10} \mathrm{PFU} / \mathrm{mL}$, and disseminated infections were found in midges fed on blood meals ranging from 5.2 to $8.2 \log _{10} \mathrm{PFU} / \mathrm{mL}$. Additionally, logistic modeling estimated that the probability of $50 \%$ of midges becoming infected (OID50) and becoming infectious (ODD50) by day 10 required infectious doses of $5.8 \log _{10} \mathrm{PFU} / \mathrm{mL}$ and $6.3 \log _{10} \mathrm{PFU} / \mathrm{mL}$, respectively, suggesting a dose-dependent infection as observed in previous studies [22], and with higher oral 
doses of VSV correlating with higher infection and dissemination rates within a single gonotrophic cycle.

In VSV-infected livestock, 6 to $9 \log _{10} \mathrm{PFU} / \mathrm{mL}$ are encountered in vesicular fluids, at the margins of damaged tissues, and in the copious amounts of saliva shed by symptomatic animals $[19,41]$. By ingesting blood in pools created within or near skin wounds, Culicoides midges likely ingest VSV from intact skin surfaces contaminated with saliva and vesicular sera, and from the vesicular lesions themselves. Based on our minimum infectious dose study, these reported viral levels would be adequate to initiate midgut and disseminated infections in more than $50 \%$ of midges that feed to repletion. Although high levels of viral RNA can be detected by RT-qPCR in the blood of pigs experimentally infected with VSV-NJ [18], viremia, as detected by cell culture, has not been reported in naturally or experimentally infected livestock [41-44]. However, it has been recently suggested that detecting infectious viruses by cell culture during RNAemia might be prevented by the inhibitory effect of heat-stable and thermolabile serum proteins [18]. It is unclear whether this cell culture inhibitory effect also alters the ability of the virus in the blood to infect insect midguts. Our minimum infectious dose results suggest that estimated viral levels in experimentally infected swine, based on RNAemia [18], would be adequate to initiate midgut and disseminated infections in $50 \%$ of midges fed to repletion.

Estimating that $C$. sonorensis midges ingest a volume of 100-150 $\mathrm{nL}$ [20,21], feeding events on blood meals with titers lower than $5 \log _{10} \mathrm{PFU} / \mathrm{mL}$ may result in fewer than one virion being ingested, lowering the chance that midges will become infected. A previous study with intrathoracic injections of $C$. sonorensis midges with $200 \mathrm{~nL}$ volumes of bluetongue virus at $3 \log _{10} \mathrm{PFU} / \mathrm{mL}$ resulted in only $35 \%$ of midges becoming infected [45]. Thus, even when bypassing the midgut infection barrier, the inoculum is minimal at these lower concentrations that it results in approximately $65 \%$ of midges receiving no virus [28]. However, having vertebrate hosts with low viral titers does not preclude animal-to-midge transmission. Culicoides midges feed opportunistically in swarms, with reported feeding rates of 110 bites per minute and with the collections of 281 fed females from a single animal after only a 10-min interval [46-49]. Thus, it is expected that even at a $30.8 \%$ midgut infection rate after ingesting 100-150 $\mathrm{nL}$ of a meal containing $3.2 \log _{10} \mathrm{PFU} / \mathrm{mL}$ VSV from an infected animal, a significant number of midges in a feeding swarm will become infected [28].

An additional determinant on vector competence measured in this study was feeding on non-infectious blood meals after ingestion of an infectious blood meal. Subsequent blood-feeding events have been shown to decrease the extrinsic incubation period (EIP) and increase the proportion of infectious vectors, as seen in Leishmania-infected sandflies [50] and in Zika- [32], dengue- [32], and chikungunya-infected [31,32] Aedes aegypti mosquitoes. Conversely, in Anopheles gambiae mosquitoes, a subsequent blood meal either did not affect the number of Plasmodium oocysts in terms of parasite survival and growth or negatively impacted oocyst development [35]. Our results indicate that additional blood-feeding enhances VSV replication in C. sonorensis midges, suggesting that successive non-infectious blood-feeding may enhance the vector's likelihood of transmission either as a result of higher titers or potentially shorter EIPs as seen in mosquitoes, and confirming the importance of feeding behavior on vector-virus infection dynamics. Subsequent blood meals may induce extra midgut expansion and increase the number of micro-perforations in the basal lamina over time, enhancing the likelihood of virus escape [31,32]. Additional research has shown that once the arbovirus has established an infection in the vector gut, its ability to escape this barrier may not be dependent on enhanced viral replication but may be rather strongly influenced by blood-induced changes in the midgut epithelium [31,51,52]. In nature, Culicoides midges may ingest several blood meals to maximize the number of egg-laying cycles throughout their lifespan $[15,16]$. Thus, this behavior enhances pathogen transmission risk by enhancing VSV infection over time and increasing the contact frequency with animal hosts [53]. 
Given the potential for enhanced distention and porosity of the midgut epithelium as a consequence of blood-feeding [31,32], increased virus titers and infection rates were expected in midges that ingested a non-infectious blood meal prior to the infectious meal (BM + VSV-BM). Surprisingly, no infection enhancement was observed when virus was initially ingested in a second meal. This may be explained by evidence that blood-feeding increases circulating hemocyte numbers [53-55] and innate immune response activation in mosquitoes $[33,35]$. Blood-fed mosquitoes are able to clear more bacteria than non-bloodfed females intrathoracically challenged with Escherichia coli [53]. Thus, we hypothesize that $C$. sonorensis midges fed on a previous non-infected blood meal may have elevated resistance to VSV infection via an increase in the number of circulating hemocytes which are then stimulated by the second (infectious) blood meal. Thus, although bloodmealinduced micro-perforations in midgut epithelium can facilitate the escape of viral progeny and enhance disseminated infections [31,32], these escaped viral particles face enhanced immune responses to limit viral replication $[32,34,56,57]$.

Lastly, we showed that increasing midge age results in significantly higher VSV titers without altering the infection rates. Studies in mosquitoes have shown that the number of hemocytes and strength of the immune response progressively declines with age $[38,54]$. This immunosenescence often results in increased entomopathogenic infections in older insects $[38,51]$. To date, very little is known about the relationship between viral infection, aging, and immunity in Culicoides midges. Based on investigations of other Dipteran vectors, we hypothesize that immune-related response activation in some of the target tissues (hemocytes, the fat body, midgut) decreases with aging, allowing increased VSV replication rates. However, the effects of immunosenescence on the competence of Dipteran vectors vary between vector species and pathogen pairing. Older Ae. aegypti had significantly higher dengue-2 virus infection rates at early time points [52], but this phenomenon was not seen in Zika virus infection rates and titers [39]. Black flies showed decreased disseminated VSV infection with increased age [56], and older Culex mosquitoes and Tsetse flies are also less capable of becoming infected with parasites they vector [57,58]. Moreover, older Ae. trivittatus and Ae. aegypti are less capable of becoming infected with filarial nematodes $[59,60]$, and older Culex tritaeniorhynchus mosquitoes exhibited less susceptibility to oral infection with West Nile Virus [61]. This age-related increased virus replication in midges was not seen in our previous study above when midges had ingested a prior blood meal and had gone through a gonotrophic cycle and were, therefore, older when fed an infectious meal. This lends further evidence that a prior blood meal increases innate immune responses to dampen what would have been enhanced viral replication in the older midges. Without consideration of potential alterations to vector competence and EIP dynamics, a vector's age at the time of pathogen acquisition is a powerful driver of reduced or enhanced likelihood of transmission due to the age-dependence of daily mortality and feeding habits over their lifespan [39].

\section{Materials and Methods}

\subsection{Virus and Cells}

Stock virus (VSV-NJ; 1982 bovine field isolate, USDA-APHIS, Ames, IA, USA) was grown in porcine epithelial cells (AG08113; Coriell Institute, Camden, NJ, USA) with Eagles MEM containing Earle's salts (Sigma, St. Louis, MO, USA) containing 2\% FBS and 100 U penicillin/streptomycin sulfate at $37^{\circ} \mathrm{C}$ with $5 \% \mathrm{CO}_{2}$. Vero MARU cells (VM; Middle America Research Unit, Panama) grown in 199E media containing 2\% FBS, $100 \mathrm{ug} / \mathrm{mL}$ strep, 100 units $/ \mathrm{ml}$ Pen, and $0.25 \mathrm{ug} / \mathrm{mL}$ amphotericin $\mathrm{B}$ at $37^{\circ} \mathrm{C}$ with $5 \% \mathrm{CO}_{2}$ were used for detecting and titering infectious virus from midge samples as described below.

\subsection{VSV Infection of Culicoides sonorensis Midges}

All experiments were performed using colonized Culicoides sonorensis midges (AK colony) maintained by USDA, Arthropod-Borne Animal Diseases Research Unit at the Center for Grain and Animal Health Research in Manhattan, KS, USA. Adult midges were 
maintained at $25 \pm 1{ }^{\circ} \mathrm{C}$ and $75 \pm 5 \% \mathrm{RH}$ in environmental chambers with a 13:11 light: dark cycle and offered $10 \%$ sucrose solution ad libitum.

Blood meals (BM) consisted of a 1:1 mixture of defibrinated sheep blood (Lampire Biological Products, Pipersville, PA, USA) and VSV stock virus (VSV-BM; infectious meal) or sheep blood alone (BM; uninfected negative control). Midges were allowed to feed on an artificial membrane feeding system [6] for $60 \mathrm{~min}$. After each meal, midges were anesthetized with $\mathrm{CO}_{2}$, and fully engorged blood-fed females were sorted from unfed and partially fed and maintained in cardboard cages with egg cups.

\subsection{Effect of Infectious Dose on C. sonorensis VSV Infection and Dissemination Rates}

To test the effects of infectious dose on VSV infection, 1-to-3-day-old females (3 replicates) were allowed to feed on six serially-diluted infectious VSV-BMs containing titers ranging from 3.2 to $8.2 \log _{10} \mathrm{PFU} / \mathrm{mL}$. VSV titer ingested by individual females was quantified immediately after feeding (time zero). Eight fully engorged midges from each virus dilution were collected individually in $500 \mu \mathrm{L}$ of antibiotic medium (199E cell culture medium containing $2 \%$ FBS and $400 \mathrm{U} / \mathrm{mL}$ penicillin, $400 \mu \mathrm{g} / \mathrm{mL}$ streptomycin, $200 \mu \mathrm{g} / \mathrm{mL}$ gentamycin, $5 \mu \mathrm{g} / \mathrm{mL}$ ciprofloxacin, $5 \mu \mathrm{g} / \mathrm{mL}$ amphotericin B) and stored at $-80^{\circ} \mathrm{C}$ until further processing. The remaining fully engorged females were sorted into cardboard cages, maintained for 10 days, collected individually with heads separated from bodies ( $n=22$ per viral dilution) in $300 \mu \mathrm{L}$ of TRIzol (Invitrogen, Waltham, MA, USA; Thermo Fisher Scientific, Inc., Waltham, MA, USA) for reverse transcriptase quantitative PCR (RT-qPCR), and stored at $-80^{\circ} \mathrm{C}$ until further processing.

\subsection{Effect of Subsequent or Prior Non-Infectious Blood Meals on C. sonorensis VSV Infection Rates and Titers}

To test the effects of subsequent BMs on VSV infection (Figure 3a), 1-to-3-day old females (4 replicates) were allowed to feed on a VSV-BM $\left(8.2 \log _{10} \mathrm{PFU} / \mathrm{mL}\right)$. Fully engorged females were sorted into two cardboard maintenance cages with egg cups. At 4 and 8 days, after GC-1 and GC-2, one cage was provided with a BM. As above, fully engorged females were selected and placed in new cages after each feeding. From each cage, on days 8 and 12 , midges ( $n=44$ per group) were collected individually in TRIzol or antibiotic medium and stored until processing, as above.

To test the effects of a prior BM on VSV infection (Figure 3b), 1-to-3-day-old females (3 replicates) were either provided a BM or maintained on $10 \%$ sucrose. At four days, BM and sucrose-fed midges were provided a VSV-BM $\left(8.2 \log _{10} \mathrm{PFU} / \mathrm{mL}\right)$. Fully engorged females were sorted, maintained for eight days on $10 \%$ sucrose, sampled ( $n=32$ per group) as above, and stored at $-80{ }^{\circ} \mathrm{C}$ until further processing.

\subsection{Effect of $C$. sonorensis age on VSV Infection Rates and Titers}

To test the effects of age on VSV infection (Figure 3c), 1-to-3-day-old females ('younger'; 3 replicates) were provided a VSV-BM $\left(8.2 \log _{10} \mathrm{PFU} / \mathrm{mL}\right)$ and held for eight days. Simultaneously, a second group of 5-to-8-day-old females ('older'; 3 replicates), that had been maintained on $10 \%$ sucrose solution, were provided a VSV-BM. Fully engorged females from both groups were selected, sorted, maintained for an additional eight days, then sampled ( $n=32$ per group) and stored until processing, as above.

\subsection{RNA Extraction and RT-qPCR for Detection of VSV}

Frozen TRIzol midge samples were thawed on ice, two $2.4 \mathrm{~mm}$ stainless steel beads (Omni Inc., Kennesaw, GA, USA) were added, and tubes were homogenized by shaking at $3.1 \mathrm{~m} / \mathrm{s}$ with a Bead Mill Homogenizer (Omni Inc.). Samples were centrifuged at $12,000 \times \mathrm{g}$ for $6 \mathrm{~min}$ to pellet debris. Total RNA was extracted using Trizol-BCP (1-bromo3chloropropane; ThermoFisher Life Technologies, Waltham, MA, USA), and RNA extracts were analyzed using TaqMan Fast Virus 1-Step MasterMix (Applied Biosystems, Waltham, MA, USA; ThermoFisher Scientific, Inc., Waltham, MA, USA) in an RT-qPCR assay detecting the L segment as previously described [6]. Standard curves and calculation of Ct values 
were carried out with the 7500 Fast Dx software (Applied Biosystems, Waltham, MA, USA; Thermo Fisher Scientific, Inc.). RT-qPCR reactions with $\mathrm{Ct} \leq 36.5$ were considered positive for VSV RNA [6]. To limit inter-run variations and consider the variable efficiency of each assay, a standard positive control with of known ssRNA concentration was used in every RT-qPCR assay. Cycle threshold $(\mathrm{Ct})$ values plotted against the $\log _{10}$ of ssRNA VSV ng and the linear regression $(y=-3.30578 x+11.02683)$ allowed determination of viral genomic equivalents per midge [6].

\subsection{Plaque Assays and Cytopathic Effect}

To isolate infectious virus, frozen midges stored in $500 \mu \mathrm{L}$ antibiotic media were thawed on ice and individually homogenized as above. Samples were centrifuged at $12,000 \times g$ for $6 \mathrm{~min}$ to pellet debris. Observation of cytopathic effects (CPE) after two passages was used to indicate infectious virus within that sample [6]. All homogenates with positive $\mathrm{CPE}$ at the first passage were further analyzed to determine infectious virus titer by standard plaque assay of the original homogenate.

\subsection{Statistical Analysis}

Data were pooled from the independent replicates of each experiment. Infection rates were calculated by dividing the number of positive midges by the total number of midges tested by RT-qPCR. Dissemination rates were calculated as the proportion of viral-RNA positive heads out of the total number of positive bodies assayed. Non-parametric tests (Kruskal-Wallis, Mann-Whitney) were used to compare Ct values and the proportion of infected midges. Non-linear regression analyses were used to evaluate the results of the oral dose experiment. GraphPad Prism version 9 (GraphPad Software Inc., San Diego, CA, USA) was used for statistical analysis and the creation of graphs.

\section{Conclusions}

This work emphasizes the importance of incorporating vector biology in understanding virus-vector interactions for VSV transmission dynamics and predictive modeling. Our results showed relatively high oral infection rates even with low blood meal titers, and enhanced virus titers in both older midges, and in midges fed on subsequent blood meals after VSV infection. Understanding these variables reinforce the ideal management practice of preventing/controlling midges before they have an opportunity to feed on a host. This research highlights the importance of considering the epidemiological implications of vector biology and feeding behavior to estimate the risk of VSV and likelihood of transmission by Culicoides midges more accurately.

Supplementary Materials: The following are available online at https:/ / www.mdpi.com/article/10 .3390 / pathogens10070816/s1. Figure S1. Correlation of mean VSV titers ingested by midges and the infectious blood meal doses on which they fed. Ingested titers were determined as individual whole-body homogenates plaqued on Vero cells.

Author Contributions: Conceptualization, P.R.-L. and B.S.D.; Data curation, P.R.-L.; Formal analysis, P.R.-L., B.L.-R., and B.S.D.; Funding acquisition, B.L.-R., and B.S.D.; Investigation, P.R.-L.; Methodology, P.R.-L. and B.S.D.; Project administration, B.S.D.; Resources, B.S.D.; Supervision, B.L.-R., and B.S.D.; Validation, P.R.-L. and B.S.D.; Visualization, P.R.-L. and B.S.D.; Writing-original draft, P.R.-L.; Writing-review and editing, P.R.-L., B.L.-R., and B.S.D. All authors have read and agreed to the published version of the manuscript.

Funding: Funding was provided by USDA, ARS-Kansas State University Cooperative Agreement \#58-3020-7-025 funded by the USDA, ARS, NP103 Animal Health National Program, Project Numbers 3020-32000-010 and 3020-32000-013.

Institutional Review Board Statement: Not applicable.

Informed Consent Statement: Not applicable. 
Data Availability Statement: The data presented in this study are available on request from the corresponding authors and through the USDA Agricultural Research Information System.

Acknowledgments: We thank L. Reister-Hendricks, A. Harlan, D. Jasperson, D. Swanson, and W. Yarnell, at the Arthropod-Borne Animal Diseases Research Unit, USDA, ARS, Manhattan, KS for their technical assistance. We also thank D. Swanson and D. Nayduch for reviewing an earlier version of this manuscript. Mention of trade names or commercial products in this publication is solely for the purpose of providing specific information and does not imply recommendation or endorsement by the U.S. Department of Agriculture. The conclusions in this report are those of the authors and do not necessarily represent the views of the USDA. USDA is an equal opportunity provider and employer.

Conflicts of Interest: The authors declare no conflict of interest.

\section{References}

1. Carpenter, S.; Groschup, M.H.; Garros, C.; Felippe-Bauer, M.L.; Purse, B.V. Culicoides biting midges, arboviruses and public health in Europe. Antivir. Res. 2013, 100, 102-113. [CrossRef] [PubMed]

2. Sick, F.; Beer, M.; Kampen, H.; Wernike, K. Culicoides Biting Midges-Underestimated Vectors for Arboviruses of Public Health and Veterinary Importance. Viruses 2019, 11, 376. [CrossRef] [PubMed]

3. Rozo-Lopez, P.; Drolet, B.S.; Londoño-Renteria, B. Vesicular Stomatitis Virus Transmission: A Comparison of Incriminated Vectors. Insects 2018, 9, 190. [CrossRef]

4. $\quad$ Peck, D.E.; Reeves, W.K.; Pelzel-McCluskey, A.M.; Derner, J.D.; Drolet, B.; Cohnstaedt, L.W.; Swanson, D.; McVey, D.S.; Rodriguez, L.L.; Peters, D.P. Management Strategies for Reducing the Risk of Equines Contracting Vesicular Stomatitis Virus (VSV) in the Western United States. J. Equine Vet. Sci. 2020, 90, 103026. [CrossRef] [PubMed]

5. Peters, D.P.C.; McVey, D.S.; Elias, E.H.; Pelzel-McCluskey, A.M.; Derner, J.D.; Burruss, N.D.; Schrader, T.S.; Yao, J.; Pauszek, S.J.; Lombard, J.; et al. Big data-model integration and AI for vector-borne disease prediction. Ecosphere 2020, 11. [CrossRef]

6. Rozo-Lopez, P.; Londono-Renteria, B.; Drolet, B.S. Venereal Transmission of Vesicular Stomatitis Virus by Culicoides sonorensis Midges. Pathogens 2020, 9, 316. [CrossRef] [PubMed]

7. Campbell, C.L.; VanDyke, K.A.; Letchworth, G.J.; Drolet, B.S.; Hanekamp, T.; Wilson, W.C. Midgut and salivary gland transcriptomes of the arbovirus vector Culicoides sonorensis (Diptera: Ceratopogonidae). Insect Mol. Biol. 2005, 14, 121-136. [CrossRef]

8. Perez De Leon, A.A.; O’Toole, D.; Tabachnick, W.J. Infection of guinea pigs with vesicular stomatitis New Jersey virus Transmitted by Culicoides sonorensis (Diptera: Ceratopogonidae). J. Med. Entomol. 2006, 43, 568-573. [CrossRef]

9. Perez de Leon, A.A.; Tabachnick, W.J. Transmission of vesicular stomatitis New Jersey virus to cattle by the biting midge Culicoides sonorensis (Diptera: Ceratopogonidae). J. Med. Entomol. 2006, 43, 323-329. [CrossRef]

10. Drolet, B.S.; Campbell, C.L.; Stuart, A.M.; Wilson, W.C. Vector competence of Culicoides sonorensis (Diptera: Ceratopogonidae) for vesicular stomatitis virus. J. Med. Èntomol. 2005, 42, 409-418. [CrossRef]

11. Letchworth, G.; Rodriguez, L.; Del Cbarrera, J. Vesicular Stomatitis. Vet. J. 1999, 157, 239-260. [CrossRef]

12. Hanson, R.P.; Estupiñan, J.; Castañeda, J. Vesicular stomatitis in the Americas. Bull.-Off. Int. Epizoot. 1968, 70, 37-47.

13. Rodríguez, L.L. Emergence and re-emergence of vesicular stomatitis in the United States. Virus Res. 2002, 85, 211-219. [CrossRef]

14. Rodríguez, L.L.; Bunch, T.A.; Fraire, M.; Llewellyn, Z.N. Re-emergence of Vesicular Stomatitis in the Western United States Is Associated with Distinct Viral Genetic Lineages. Virology 2000, 271, 171-181. [CrossRef]

15. Boorman, J. Biting midges (Ceratopogonidae). In Medical Insects and Arachnids; Lane, R.P., Crosskey, R.W., Eds.; Springer Netherlands: Dordrecht, The Netherlands, 1993; pp. 288-309. [CrossRef]

16. Linley, J.R.; Davies, J.B. Sandflies and Tourism in Florida and the Bahamas and Caribbean Area. J. Econ. Ėntomol. 1971, 64, 264-278. [CrossRef]

17. Lehiy, C.; Reister-Hendricks, L.M.; Ruder, M.G.; McVey, D.S.; Drolet, B.S. Innate mammalian immune responses to culicoides feeding. Parasites Vectors 2018. In Review. [CrossRef]

18. Velazquez-Salinas, L.; Pauszek, S.J.; Stenfeldt, C.; O’Hearn, E.S.; Pacheco, J.; Borca, M.V.; Verdugo-Rodriguez, A.; Arzt, J.; Rodriguez, L.L. Increased Virulence of an Epidemic Strain of Vesicular Stomatitis Virus Is Associated With Interference of the Innate Response in Pigs. Front. Microbiol. 2018, 9, 1891. [CrossRef]

19. Brandly, C.A.; Hanson, R.P. Epizootiology of Vesicular Stomatitis. Am. J. Public Health Nations Health 1957, 47, 205-209. [CrossRef]

20. Leprince, D.J.; Higgins, A.J.; Church, E.G.; Issel, C.J.; McManus, J.M.; Foil, L.D. Body size of Culicoides variipennis (Diptera: Ceratopogonidae) in relation to bloodmeal size estimates and the ingestion of Onchocerca cervicalis (Nematoda: Filarioidea) microfiliariae. J. Am. Mosq. Control. Assoc. 1989, 5, 100-103.

21. de Beer, C.J.; Boikanyo, S.N.B.; Venter, G.J.; Mans, B. The applicability of spectrophotometry for the assessment of blood meal volume inartificially fed Culicoides imicola in South Africa. Med. Vet.-Èntomol. 2021, 35, 141-146. [CrossRef]

22. Kramer, L.D.; Houk, E.J.; Hardy, J.L.; Presser, S.B. Dissemination Barriers for Western Equine Encephalomyelitis Virus in Culex Tarsalis Infected after Ingestion of Low Viral Doses *. Am. J. Trop. Med. Hyg. 1981, 30, 190-197. [CrossRef]

23. Nunamaker, R.A.; De León, A.A.P.; Campbell, C.L.; Lonning, S.M. Oral infection of Culicoides sonorensis (Diptera: Ceratopogonidae) by vesicular stomatitis virus. J. Med. Èntomol. 2000, 37, 784-786. [CrossRef] 
24. Kramer, L.D.; Ciota, A.T. Dissecting vectorial capacity for mosquito-borne viruses. Curr. Opin. Virol. 2015, 15, 112-118. [CrossRef]

25. Agarwal, A.; Parida, M.; Dash, P.K. Impact of transmission cycles and vector competence on global expansion and emergence of arboviruses. Rev. Med. Virol. 2017, 27, e1941. [CrossRef]

26. Bennett, K.E.; Farfan-Ale, A.J.; Fernandez-Salas, I.; Black, W.C.; Higgs, S.; Beaty, B.J.; Muñoz, M.D.L.; Olson, E.K. Variation in vector competence for dengue 2 virus among 24 collections of Aedes aegypti from Mexico and the United States. Am. J. Trop. Med. Hyg. 2002, 67, 85-92. [CrossRef]

27. Vazeille-Falcoz, M.; Rodhain, F.; Chungue, E.; Failloux, A.B.; Mousson, L. Variation in oral susceptibility to dengue type 2 virus of populations of Aedes aegypti from the islands of Tahiti and Moorea, French Polynesia. Am. J. Trop. Med. Hyg. 1999, 60, 292-299. [CrossRef]

28. Lord, C.C.; Rutledge, C.R.; Tabachnick, W.J. Relationships between host viremia and vector susceptibility for arboviruses. J. Med. Entomol. 2006, 43, 623-630. [CrossRef]

29. Mullens, B.A.; Schmidtmann, E.T. The Gonotrophic Cycle of Culicoides Variipennis (Diptera: Ceratopogonidae) and its Implications in Age-Grading Field Populations in New York State, USA. J. Med. Ėntomol. 1982, 19, 340-349. [CrossRef]

30. Okuda, K.; de Almeida, F.; Mortara, R.; Krieger, H.; Marinotti, O.; Bijovsky, A.T. Cell death and regeneration in the midgut of the mosquito, Culex quinquefasciatus. J. Insect Physiol. 2007, 53, 1307-1315. [CrossRef] [PubMed]

31. Dong, S.; Balaraman, V.; Kantor, A.M.; Lin, J.; Grant, D.G.; Held, N.L.; Franz, A.W.E. Chikungunya virus dissemination from the midgut of Aedes aegypti is associated with temporal basal lamina degradation during bloodmeal digestion. PLOS Neglected Trop. Dis. 2017, 11, e0005976. [CrossRef] [PubMed]

32. Armstrong, P.M.; Ehrlich, H.Y.; Magalhaes, T.; Miller, M.R.; Conway, P.J.; Bransfield, A.; Misencik, M.J.; Gloria-Soria, A.; Warren, J.L.; Andreadis, T.G.; et al. Successive blood meals enhance virus dissemination within mosquitoes and increase transmission potential. Nat. Microbiol. 2020, 5, 239-247. [CrossRef]

33. Bryant, W.B.; Michel, K. Blood feeding induces hemocyte proliferation and activation in the African malaria mosquito, Anopheles gambiae Giles. J. Exp. Biol. 2014, 217, 1238-1245. [CrossRef]

34. Upton, L.M.; Povelones, M.; Christophides, G.K. Anopheles gambiae blood feeding initiates an anticipatory defense response to Plasmodium berghei. J. Innate Immun. 2014, 7, 74-86. [CrossRef]

35. Kwon, H.; Reynolds, R.A.; Simões, M.L.; Dimopoulos, G.; Smith, R.C. Malaria parasite immune evasion and adaptation to its mosquito host is influenced by the acquisition of multiple blood meals. bioRxiv 2019, 801480. [CrossRef]

36. Chun, J.; Riehle, M.; Paskewitz, S.M. Effect of Mosquito Age and Reproductive Status on Melanization of Sephadex Beads in Plasmodium-Refractory and -Susceptible Strains of Anopheles gambiae. J. Invertebr. Pathol. 1995, 66, 11-17. [CrossRef]

37. Hillyer, J.F.; Schmidt, S.L.; Christensen, B.M.; Hillyer, J.F. Rapid phagocytosis and melanization of bacteria and plasmodium sporozoites by hemocytes of the mosquito aedes aegypti. J. Parasitol. 2003, 89, 62-69. [CrossRef]

38. Hillyer, J.; Schmidt, S.L.; Fuchs, J.F.; Boyle, J.P.; Christensen, B.M. Age-associated mortality in immune challenged mosquitoes (Aedes aegypti) correlates with a decrease in haemocyte numbers. Cell. Microbiol. 2004, 7, 39-51. [CrossRef]

39. Mayton, E.H.; Tramonte, A.R.; Wearing, H.J.; Christofferson, R.C. Age-structured vectorial capacity reveals timing, not magnitude of within-mosquito dynamics is critical for arbovirus fitness assessment. Parasites Vectors 2020, 13, 1-13. [CrossRef]

40. Ohm, J.R.; Baldini, F.; Barreaux, P.; Lefevre, T.; Lynch, P.A.; Suh, E.; Whitehead, S.A.; Thomas, M.B. Rethinking the extrinsic incubation period of malaria parasites. Parasites Vectors 2018, 11, 1-9. [CrossRef]

41. Stallknecht, D.E.; Perzak, D.E.; Bauer, L.D.; Murphy, M.D.; Howerth, E.W. Contact transmission of vesicular stomatitis virus New Jersey in pigs. Am. J. Vet.-Res. 2001, 62, 516-520. [CrossRef]

42. Howerth, E.W.; Mead, D.G.; Mueller, P.O.; Duncan, L.; Murphy, M.D.; Stallknecht, D.E. Experimental Vesicular Stomatitis Virus Infection in Horses: Effect of Route of Inoculation and Virus Serotype. Vet.-Pathol. 2006, 43, 943-955. [CrossRef] [PubMed]

43. Howerth, E.W.; Stallknecht, D.E.; Dorminy, M.; Pisell, T.; Clarke, G.R. Experimental Vesicular Stomatitis in Swine: Effects of Route of Inoculation and Steroid Treatment. J. Vet.-Diagn. Investig. 1997, 9, 136-142. [CrossRef] [PubMed]

44. Scherer, C.F.; O’Donnell, V.; Golde, W.T.; Gregg, D.; Estes, D.M.; Rodriguez, L.L. Vesicular stomatitis New Jersey virus (VSNJV) infects keratinocytes and is restricted to lesion sites and local lymph nodes in the bovine, a natural host. Vet. Res. 2007, 38, 375-390. [CrossRef] [PubMed]

45. Tabachnick, W.J.; MacLachlan, N.J.; Thompson, L.H.; Hunt, G.J.; Patton, J.F. Susceptibility of Culicoides variipennis sonorensis to Infection by Polymerase Chain Reaction-Detectable Bluetongue Virus in Cattle Blood. Am. J. Trop. Med. Hyg. 1996, 54, 481-485. [CrossRef]

46. Mullens, B.A.; Dada, C.E. Insects Feeding on Desert Bighorn Sheep, Domestic Rabbits, and Japanese Quail in the Santa Rosa Mountains of Southern California. J. Wildl. Dis. 1992, 28, 476-480. [CrossRef]

47. Mullens, B.A.; Gerry, A.C. Comparison of Bait Cattle and Carbon Dioxide-Baited Suction Traps for Collecting Culicoides variipennis sonorensis (Diptera: Ceratopogonidae) and Culex quinquefasciatus (Diptera: Culicidae). J. Med. Èntomol. 1998, 35, 245-250. [CrossRef]

48. Tempelis, C.H.; Nelson, R.L. Blood-Feeding Patterns of Midges of the Culicoides Variipennis Complex in Kern County, California1. J. Med. Èntomol. 1971, 8, 532-534. [CrossRef]

49. Gerry, A.C.; Monteys, I.V.S.; Vidal, J.-O.M.; Francino, O.; Mullens, B.A. Biting Rates ofCulicoidesMidges (Diptera: Ceratopogonidae) on Sheep in Northeastern Spain in Relation to Midge Capture Using UV Light and Carbon Dioxide-Baited Traps. J. Med. Èntomol. 2009, 46, 615-624. [CrossRef] 
50. Serafim, T.D.; Coutinho-Abreu, I.; Oliveira, F.; Meneses, C.; Kamhawi, S.; Valenzuela, J.G. Sequential blood meals promote Leishmania replication and reverse metacyclogenesis augmenting vector infectivity. Nat. Microbiol. 2018, 3, 548-555. [CrossRef]

51. Castillo, J.; Brown, M.R.; Strand, M.R. Blood Feeding and Insulin-like Peptide 3 Stimulate Proliferation of Hemocytes in the Mosquito Aedes aegypti. PLOS Pathog. 2011, 7, e1002274. [CrossRef]

52. Castillo, J.; Robertson, A.; Strand, M. Characterization of hemocytes from the mosquitoes Anopheles gambiae and Aedes aegypti. Insect Biochem. Mol. Biol. 2006, 36, 891-903. [CrossRef]

53. Baton, L.A.; Robertson, A.; Warr, E.; Strand, M.R.; Dimopoulos, G. Genome-wide transcriptomic profiling of Anopheles gambiae hemocytes reveals pathogen-specific signatures upon bacterial challenge and Plasmodium berghei infection. BMC Genom. 2009, 10, 257. [CrossRef]

54. Hillyer, J.F. Insect immunology and hematopoiesis. Dev. Comp. Immunol. 2016, 58, 102-118. [CrossRef]

55. Styer, L. Effect of Mosquito Age and Mortality Patterns on Transmission of Dengue-2 Virus by Aedes Aegypti. Ph.D. Thesis, University of California Davis, Davis, CA, USA, ProQuest Information and Learning Company, Michigan. 2003.

56. Howerth, E.W.; Mead, D.G.; Stallknecht, D.E. Immunolocalization of Vesicular Stomatitis Virus in Black Flies (Simulium vittatum). Ann. N. Y. Acad. Sci. 2002, 969, 340-345. [CrossRef]

57. Aksoy, S.; Weiss, B.L.; Attardo, G.M. Trypanosome transmission dynamics in tsetse. Curr. Opin. Insect Sci. 2014, 3, 43-49. [CrossRef]

58. Pigeault, R.; Nicot, A.; Gandon, S.; Rivero, A. Mosquito age and avian malaria infection. Malar. J. 2015, 14, 383. [CrossRef]

59. Ariani, C.V.; Juneja, P.; Smith, S.; Tinsley, M.C.; Jiggins, F.M. Vector competence of Aedes aegypti mosquitoes for filarial nematodes is affected by age and nutrient limitation. Exp. Gerontol. 2015, 61, 47-53. [CrossRef]

60. Christensen, B.M.; Lafond, M.M.; Christensen, L.A. Defense Reactions of Mosquitoes to Filarial Worms: Effect of Host Age on the Immune Response to Dirofilaria immitis Microfilariae. J. Parasitol. 1986, 72, 212. [CrossRef]

61. Baqar, S.; Hayes, C.G.; Ahmed, T. The effect of larval rearing conditions and adult age on the susceptibility of Culex tritaeniorhynchus to infection with West Nile virus. Mosq. News 1980, 40, 165-171. 